\title{
NOTES
}

\section{A UNIFORM WAY TO REPORT DATABASE RESULTS}

\author{
R.W.G. Hunen,
}

Delft University of Technology

\begin{abstract}
During the past few years, many database results have been reported in this Journal and in other publications. Some database figures are agreed upon by the researchers, other figures have been shown to be incorrect or are still subjects of discussion. One of the problems is that the exact figures as published may depend on how the database is constructed. Some researchers tend to include more reflections in the database construction than others in order to reduce the amount of work to be performed.
\end{abstract}

Under these circumstances it may well occur that the figures presented are different but still correct within their respective contexts; of course, they are then difficult to compare. The obvious solution to this problem is to convert the figures to counts in terms of the full board without any reflections. This makes results strictly comparable and puts an end to all discussions which reflections should be included.

\section{MORE TRUTH ON KBBK DATABASE RESULTS}

\author{
I.S. Herschberg and H.J. van den Herik \\ Delft University of Technology
}

It is perhaps personally saddening but certainly scientifically worthwhile to be forced to retract ones results. Accordingly, we are glad to refute, in part, most of the numbers of WTM positions in the KBBK endgame as published by us (Van den Herik and Herschberg, 1985). The correction of these numbers has been initiated by Hans Zellner's (1986a) work, about which he corresponded with the authors, while confirmation has come from one of our graduate students, Dirk Jan Out (1987).

Perhaps it is just as well to mention here that the correction is numerical only and applies only to table 1 of Van den Herik and Herschberg (1985, p. 144). The main results stand: the maximin for KBBK is 19 moves; the 16 (reflecting up to 120) positions with a 19-move maximin (ibid., p. 145) are correct as is the sample mate; likewise, our refutation of the Berger position as a maximin of the KBBK endgame stands unchallenged, as do our improvements on Berger's analyses.

With admirable diligence, Hans Zellner (1986b) wrote to inform us of a large number of discrepancies in the figures for the numbers of mate-in- $n$ positions. In fact, he only was able to confirm our results for $n=$ $3,4,17,18$ and 19. To quote but one instance, (mate-in-1), for Zellner numbered 1083 positions, whereas we had published 1024 .

The matter seemed important enough to be re-investigated independently, a task willingly undertaken by D.J. Out as a research student. (Ken Thompson, though normally oracular in these matters, responded to a letter by us stating that he had not any pertinent data on KBBK directly available.)

D.J.Out started his research by confronting Zellner's (1986b) results with those published by us and his own manual results which gave him 1153 mate-in-1 positions. Since these differed by exactly 70 from Zellner's number the suspicion naturally arose that Zellner had overlooked a class of positions numbering 
70. This proved to be the case : Zellner's program had disregarded 70 mate-in-1 positions where mate was effected by a king move, namely those known as mate by discovery. This was later confirmed by Zellner (1987).

Since Zellner and our database agreed on the number of illegal positions and on the number of drawn positions and the latter had also independently been checked manually, the problem could be pinpointed with some confidence to the generation of the mate-in-1 positions. Indeed an abstruse error was found in this class: with the King on d1, an escape was possible by his moving to e1 or e2, in spite of the squares being covered by Bishops. Upon correcting this error's consequences a large part of Zellner's (1986b) results were confirmed, with only two discrepancies remaining.

In table 1, D.J. Out's results are reproduced; they gain credibility by Zellner's being largely concordant. Needless to say, these results invalidate and replace table 1 (of Van den Herik and Herschberg (1985)).

\begin{tabular}{|r|r||r|r|}
\hline $\begin{array}{c}\text { \# of moves } \\
\text { to mate }\end{array}$ & $\begin{array}{r}\text { \# of canonical } \\
\text { WTM positions }\end{array}$ & $\begin{array}{c}\text { \# of moves } \\
\text { to mate }\end{array}$ & $\begin{array}{c}\text { \# of canonical } \\
\text { WTM positions }\end{array}$ \\
\hline 1 & 1,153 & 11 & 37,855 \\
2 & 391 & 12 & 43,619 \\
3 & 3,446 & 13 & 53,097 \\
4 & 2,742 & 14 & 53,884 \\
5 & 5,504 & 15 & 49,443 \\
6 & 5,686 & 16 & 39,543 \\
7 & 8,764 & 17 & 19,182 \\
8 & 13,134 & 18 & 2,411 \\
9 & 19,045 & 19 & 16 \\
10 & 27,877 & & \\
\hline
\end{tabular}

Table 1: Numbers of WTM canonical positions in the KBBK endgame

The number of legitimate won canonical positions is The number of drawn canonical positions is The number of illegitimate canonical positions is The total number of canonical positions is
386,792

112

268,456

655,360

\begin{tabular}{|r|r||r|r|}
\hline $\begin{array}{c}\text { \# of moves } \\
\text { to mate }\end{array}$ & $\begin{array}{c}\text { \# of the full-board } \\
\text { WTM positions }\end{array}$ & $\begin{array}{c}\text { \# of moves } \\
\text { to mate }\end{array}$ & $\begin{array}{c}\text { \# of the full-board } \\
\text { WTM positions }\end{array}$ \\
\hline 1 & 6,312 & 11 & 249,656 \\
2 & 2,608 & 12 & 294,584 \\
3 & 14,936 & 13 & 354,760 \\
4 & 18,432 & 14 & 360,536 \\
5 & 30,672 & 15 & 316,056 \\
6 & 37,512 & 16 & 246,072 \\
7 & 56,808 & 17 & 109,360 \\
8 & 86,216 & 18 & 13,448 \\
9 & 124,264 & 19 & 120 \\
10 & 181,256 & & \\
\hline
\end{tabular}

Table 2: Numbers of full-board WTM positions. The results are due to Hans Zellner.

D.J. Out, in pursuit of these numbers, discovered two further interesting facts. The first fact to come to light was that the drawn positions, concordantly found to be 112, could be immediately distinguished into 94 impossible positions and 18 potentially possible ones.

In this context an impossible position is defined to be one such that it has no legal predecessor move. One

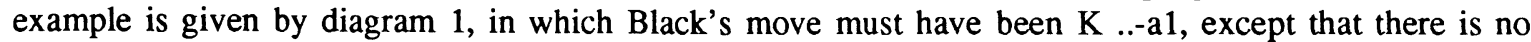


possible square the King could have moved from. By extension the same applies to diagram 2, where clearly Black's prior move has been Kb1-a1, but there is no legal predecessor move for White. Nor, we infer, can it be excluded that the problem of there being no legal predecessor move(s) is necessarily confined to drawn or mate-in-1 positions; the same danger may be lurking, more generally, in mate-in- $n$.

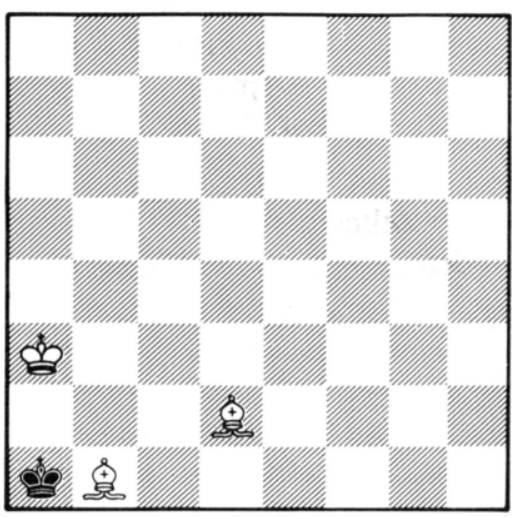

Diagram 1

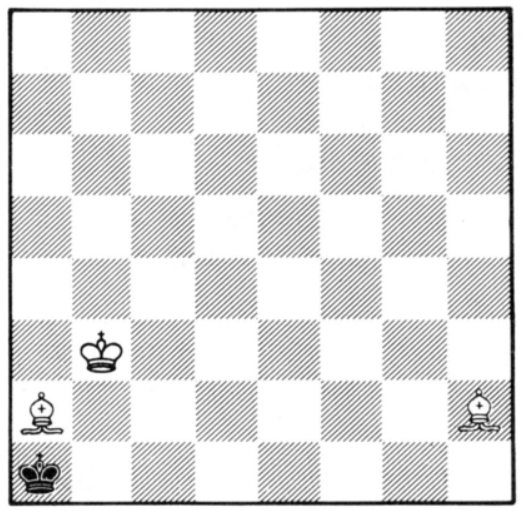

Diagram 2

The second fact to be brought out by his research was the danger of applying symmetries indiscrimately. Diagram 3 is, but for symmetry (a 90-degree rotation), a predecessor of diagram 2, with the subtle difference that diagram 3 can be reached legally whereas diagram 2 has no two-ply retrograde predecessors.

Disregarding that diagram 3 represents a mate-in-1 position, it clearly shows the danger of reflections without prior reflection, because of $1 . \mathrm{g} 7+\mathrm{Kh} 72 . \mathrm{g} 8$

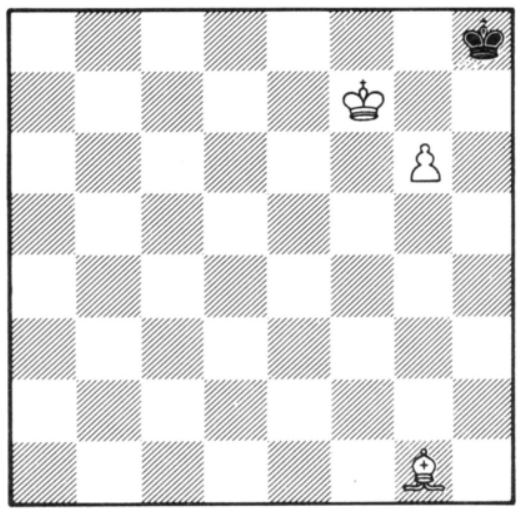

Diagram 3
(B)+ Kh8.

With hindsight we are forced to conclude that the database-construction problem may have been inadequately formulated so far. For practical play, it hardly matters whether impossible positions are included in the database: on these particular positions, the database will never be consulted. For statistics accounting for an endgame, it is vital that impossible positions are are carefully excluded because they may well distort an endgame's results, as they do when the number of drawn positions, though small in itself, is drastically reduced by confining oneself to possible positions.

Next to supporting Hünen's (1987) request of presenting database results in a uniform manner for the full board (see table 2), we now append a secondary request, viz. that all positions reported shall have arisen legally. We are quite aware that the retrograde analysis to establish the property 'possible' is delicate and laborious; nevertheless, we incline to impose it as the burden of avoiding possibly gross distortions.

\section{References}

Hünen, R.W.G. (1987). A Uniform Way to Report Database Results, ICCA Journal, Vol. 10, No. 2 , p. 91. Out, D.J. (1987). Taakverslag KBBK-eindspel. Internal Report, Delft University of Technology.

Van den Herik, H.J. and Herschberg, I.S. (1985). Elementory Theory Improved, A Conjecture Refuted. ICCA Journal, Vol. 8, No. 3, pp. 141-149.

Zellner, H. (1986a). Compressing Databases down to Micro Size. ICCA Journal, Vol. 9, No. 4, pp. 199200.

Zellner, H. (1986b). Personal Communication (September 28, 1986 and September 30, 1986).

Zellner. H. (1987). Personal Communication (April 4, 1987). 